\title{
Mobil Uygulama Etkileşimli Entegre Websitesi Tasarımı: Güvenlik ve Ölçeklenebilirlik
}

\author{
Necla BANDIRMALI ERTÜRK* \\ Bandırma Onyedi Eylül Üniversitesi, Bilgisayar Mühendisliği Bölümü,, Bandırma, Balıkesir \\ (ORCID: 0000-0002-3513-7846)
}

\begin{abstract}
$\ddot{O} z$
$\mathrm{Bu}$ makalede mobil uygulama etkileşimli entegre websitesi uygulama paradigması için etkileşimli tasarım, güvenlik ve ölçeklenebilirlik boyutları incelenmektedir. Geleneksel çözümlere kıyasla önemli avantajlara sahip olan bu sistem mimarisi ve yazılımlarıyla, yerel/küresel ağ üzerinden işlem ve iletişim gerektiren bankacılıktan sigortaya, e-ticaretten e-devlete, sağlıktan seyahate, eğitimden savunmaya kadar tüm sektörler için hayatın her evresinde yüksek sunucu-istemci başarımı mümkün görülmektedir. Çalışma sonuçları, yüksek kullanıcı sayısı ya da anlık işlem sayısı artışlarını da beraberinde getiren mobil uygulamaların değişik istekleri karşılanırken, hem güvenlik hem de ölçeklenebilirlik boyutlarının birlikte ve öncelikle ele alınmasının zorunlu olduğunu göstermektedir.
\end{abstract}

Anahtar kelimeler: Ölçeklenebilirlik, Güvenlik, Etkileşimli Tasarım, Websitesi, Mobil Uygulama.

\section{Interactive Mobile Application Integrated Website Design: Security and Scalability}

\begin{abstract}
This paper focuses on interactive design, security and scalability issues for interactive mobile application integrated website design paradigm. With this system architecture and software, which has significant advantages compared to traditional solutions, an extraordinary server-client performance is possible considering all sectors at every stage of life from banking to insurance, e-commerce to e-government, health to travel, education to military, which all require transactions and communications over local/global networks. The results of this presented study conclude that both security and scalability dimensions together should be dealt with first and foremost, while meeting the various requirements of mobile applications, which may bring about significant increases in the number of users or instant transactions.
\end{abstract}

Keywords: Scalability, Security, Interactive Design, Website, Mobile Application.

\section{Giriş}

Entegre mobil uygulama ve websitesi çözümlerinin kullanımı hızla artmaktadır. Tüm kurum ve kuruluşların, bu etkin sistem mimarisi yaklaşımı ile kullanıcıların ya da müşterilerin istedikleri bilgilere her yerden ve her an erişme taleplerini karşılamaları mümkün görülmektedir. Bu kapsamda, genel Mobil Yazılım Geliştirme Yaşam Döngüsü (MYGYD) evreleri [1] ve entegre mobil uygulama-web sistem mimarisindeki yeni yaklaşımlar açısından tasarım zorlukları ile firsatlarının incelendiği bu makalede, araştırmacılar ve sektörün, kullanıcı ihtiyaçlarına etkin cevap verilmesine, artan mobil uygulama ve websitesi isterlerinin karşılanmasına ve teknik karmaşıklıkların aşılmasına yönelik çözüm önerileri değerlendirilmektedir.

Mobil uygulamaları etkileşimli bir websitesi ile entegre edecek etkili ve yüksek başarımlı bir sistem (Web-App) tasarımı beraberinde değişik teknik güçlükleri de getirmektedir. Bu süreçlerde çok fazla sayıda üzerinde durulması gereken bileşen bulunmakla birlikte, etkileşim, ölçeklenebilirlik ve

*Sorumlu yazar: nerturk@ bandirma.edu.tr

Geliş Tarihi: 31.12.2020, Kabul Tarihi: 01.03.2021 
güvenlik en önemli unsurlar olarak geçerliliğini korumaktadır. Gerçekleştirilmekte olan akademik ve profesyonel tüm araştırmalar ve ticari ürün çalışmaları göstermektedir ki hızlı ve az çaba ile hedefe ulaştıracak komple bir yöntem henüz bulunmamaktadır.

Son dönemde hızla gelişmekte olan mobil uygulamaların teknoloji odaklı günlük hayattaki yeri, özellikle yeni websitesi tasarımları ile birlikte oluşturulan çözümler yoluyla kullanıcı etkileşimli bir evreye geçmiş bulunmaktadır (Şekil 1).

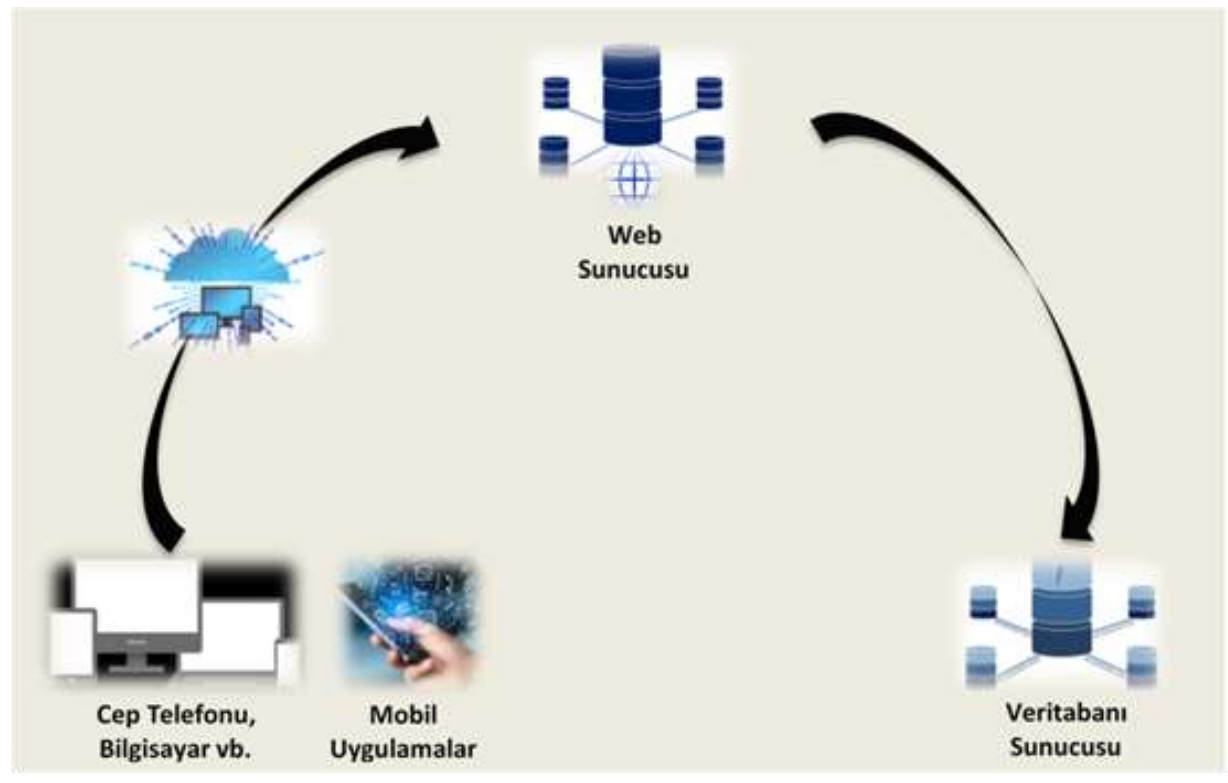

Şekil 1. Mobil uygulama etkileşimli web mimarisi

\section{Web Uygulama Sistemleri ve Websitesi Tasarımı}

Tüm sektörel alanlara özel yazılımların olduğu gibi, web teknolojilerine dayalı web sistemlerinin de gelişim süreçlerinde aşması gereken önemli sorunları bulunmaktadır. Bunlar genel olarak mimari, kavramsal tasarım ve teknoloji başlıkları altında gruplandırılır.

Web tabanlı çevrimiçi sistemlerin geliştirilmesi, birçok kurum, kuruluş, firma veya organizasyonun iş stratejisi için giderek daha kritik hale gelmektedir. Bu durum bir yazılım geliştirme şekli olarak görünmekle birlikte, iş modelleri ve buna bağlı gereksinimler açısından benzersiz özelliklere sahiptir.

Web tabanlı uygulamaların, bir kuruluşun müşterileri, hedef kitlesi ve diğer dış paydaşları ile olan etkileşiminin niteliği üzerinde önemli bir etkisi bulunmaktadır.

Web sistemleri hem teknik hem de yapısal açıdan benzersiz özellikleri ile geleneksel yazılım sistemlerinden hızla farklılaşmaktadır. Örneğin, web sistemlerinin teknik yapısı, zorlu bir işletme mimarisini hem karmaşık bir bilgi mimarisi hem de çok sayıda bileşen tabanlı teknik mimari ile birleştirmektedir (Şekil 2).

Web sistem tasarımcıları açısından güncel eğilimler aşağıdaki başlıklar altında siniflandirılabilir:

- Websitesi tasarımı

- Web uygulama tasarim1

- Duyarl1/uyumlu (responsive) web tasarımı

- E-ticaret websitesi tasarımı

- Websitesi yeniden tasarımı

- Açı1ış web sayfası tasarımı.

Websitesi geliştirme konusundaki nitelikli yaklaşımlar ve hizmetler, kuruluşların işlerini ve organizasyonlarını başarıya götürmelerine yardımcı olmaktadır. $\mathrm{Bu}$ açıdan geliştirme süreçleri, ihtiyaçları canlı bir websitesine dönüştürmenin yanı sıra tüm kurumsal ve kullanıcı gereksinimlerini karşılamak için yeni fikirler ve düşünceler üretme konusunda uzmanlık gerektirmektedir. 


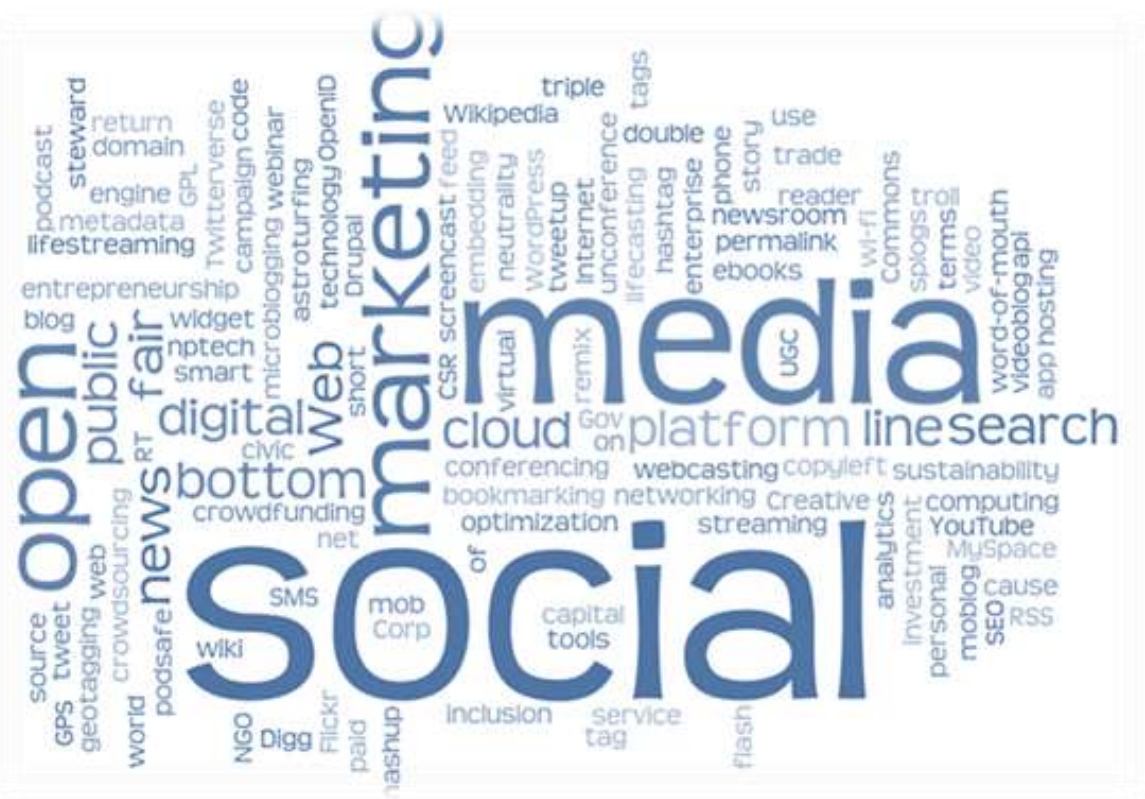

Şekil 2. Web trendleri (Serbest alıntı: https://pixabay.com/tr/illustrations/seo-web-pazarlama-618434/)

Lennart de Ridder (2019) son dönemlerdeki yenilikçi web tasarım eğilimlerini on başlıkta sinıflandirmaktadır [2]:

- Siyah-beyaz paletler

- Doğal ve organik şekiller

- Ekranda şerifler

- Aksaklık sanatı

- Mikro etkileşimler

- Sohbet robotları (chatbots)

- Daha da fazla video içeriği

- Minimalizm

- Başparmak dostu gezinme

- Çeşitlilik.

Literatürde yer alan bir başka çalışmada ise ses arabirimleri, görsel arama ve Alexa'nın öncüleri olduğu ve aşağıda sıralanan son dönem web tasarım eğilimleri farklı bir bakış açısı ile sunulmaktadır [3]:

- Çizim ile tekil bir ses oluşturma

- Tipografi tabanlı yerleşim

- Değişken yazı tipleri

- Dekore edilmiş, artırılmış ve büyük paragraflar

- Animasyon: İkincil elemanlar ve organik hareket

- Sevimli mikro etkileşimler ve mini oyunlar

- Acımasızlık ve maksimalizm (evcilleştirilen vahşi unsurlar)

- Görüntü efektleri (bozulma ve dalga etkileri)

- Bas/basill tut ve düz git

- Bağımsız tasarımcılar ve yenilikçi geliştiriciler

- Kişiliğe sahip renk şemaları

- Karışık 2 veya 3 boyutlu öğeler

- Yapay zekâ ve makine öğrenmesi

- Görsel yardımcılar

- Daha az uygulama ve daha fazla çoklu platform entegrasyonu

- Komut ses arayüzleri

- Görsel arama

- Artırılmış gerçeklik dönüşümü ve içerik oluşturma. 
Websitesi tasarımlarının öncelikli amacı, tasarımın bizatihi kendisi olmaktan ziyade, web içeriğinin daha etkili, okunaklı ve anlaşılır bir şekilde hedef kitleye aktarılmasını sağlamaktır. Bu kapsamda, masaüstü bilgisayarlardan dizüstü bilgisayarlara, mobil telefonlardan giyilebilir cihazlara kadar değişik platformlarda hiçbir fark olmaksızın web içeriğini sunabilmek önemlidir [4]. Diğer platformlara kıyasla, mobil telefon kullanıcılarının genel internet erişimindeki son yıllarda hızla artan oranı, duyarlı websitesi tasarım çözümlerini ön plana çıkartmaktadır. Zira küçük ekranlı cihazlar, web sayfası içeriğinin ekrana sığacak şekilde uyarlanmasını gerektirmektedir. Esnek grid (akışkan), esnek görüntüler, medya sorguları ve duyarlı tipografi gibi popüler tasarım yöntemleri ve araçları, günümüzde farklı platformlar için tek web sayfası sürümü imkânı sunarken bazen kaynakların kaybına da yol açabilmektedir [5]. Bu kapsamda önerilen değişik çözümlerin hedeflerinden en önemlileri şunlardır [6]:

- Web sayfası düzeni ve imge boyutu adaptasyonu

- Mobil özellikleri algılama ve cevap verme

- Sadece gerekli web sayfası bileşenlerinin sunumu

- Mobil kullanıcılar için web sayfası elementlerini basitleştirme ve daha düşük bant genişliğine sahip imgeler

- Daha geniş ve basit gezinti/grafik bileşenleri geliştirme

- Farklı cihaz özelliklerinin tanımlanması ve kullanımı.

Birinci, İkinci ve en son Üçüncü Web Jenerasyonları ile anlamsal (semantik) web, içerik kişiselleştirme, akıllı arama, otomatik içerik üretimi konuları ön plana çıkarken, sunum ve ilişkilendirme ontolojilerinin yanı sıra Kaynak Açıklaması Çerçevesi (RDF) ve Web Ontolojisi Dili (OWL) gibi önemli teknolojiler etkin olarak kullanılmaktadır. Önümüzdeki 10 yıl içerisinde ise gelişmekte olan Web4.0 ile birlikte tüm istemci bilgisayar işletim sistemlerinin bulut bilişim altyapısında yer alması ve web katılımı kaçınılmaz bir rol oynaması beklenmektedir [4].

\section{Mobil Cihazlar ve Mobil Uygulamalar}

Yakın geçmişe kadar kişisel masaüstü bilgisayarlar (PC), World Wide Web'e (www) erişebilmek için kullanılan tek cihaz türü olarak vazgeçilmez bir çözümdü. Akı1lı telefonlar, tabletler, akıllı TV'ler, melez bilgisayarlar ve IoT gibi İnternete bağlı pek çok güçlü cihazın kullanıma sunulması ve düşen maliyetler ile birlikte bu durum son yıllarda önemli ölçüde değişmektedir [7].

Mobil cihazlarındaki küçük ekran boyutu, düşük ekran çözünürlügü, dokunmatik arayüz ve sınırlı mobil bant genişliği gibi unsurlar iyi bir mobil uygulama kullanıcı deneyiminin önündeki engeller olarak bilinmektedir [8]. Buna karşın, özellikle son yıllarda yapılan önemli araştırmalar ve çalışmalar sonucunda bir dizi öneriler ve iyi uygulamalar (best practices) literatürde yerini almış bulunmaktadır. Örneğin;

- Küçük ekranda okunması kolay, büyük metin kullanımı

- Yüklenmesi uzun zaman ve yüksek bant genişliği gerektiren aşırı ve büyük boyutlu içeriklerden kaçınma

- Kullanıcının yana kaydırma ve yakınlaştırma/uzaklaştırmasını gerektiren büyük genişlikli web sayfalarından kaçınma

- Serbest metin yazma kutularından kaçınma

- Parmakla rahatça basılabilecek kadar geniş bağlantı ve düğme kullanımı.

Mobil cihaz kullanıcılarının en temel uygulama tercihleri arasında yer alan günlük web tarama ihtiyaçları ve eğilimleri hızla artarken masaüstü kullanıcılarının web gezinme oranı azalmaktadır (Şekil 3). StatCounter.com tarafindan sunulan 2008-2014 dönemi için dünya geneli istatistikleri, bu oranların mobilde \%1'den \%33'e yükselerek, masaüstünde ise \%99'dan \%61'e gerileyerek hızla değiştiğini göstermektedir [9]. 


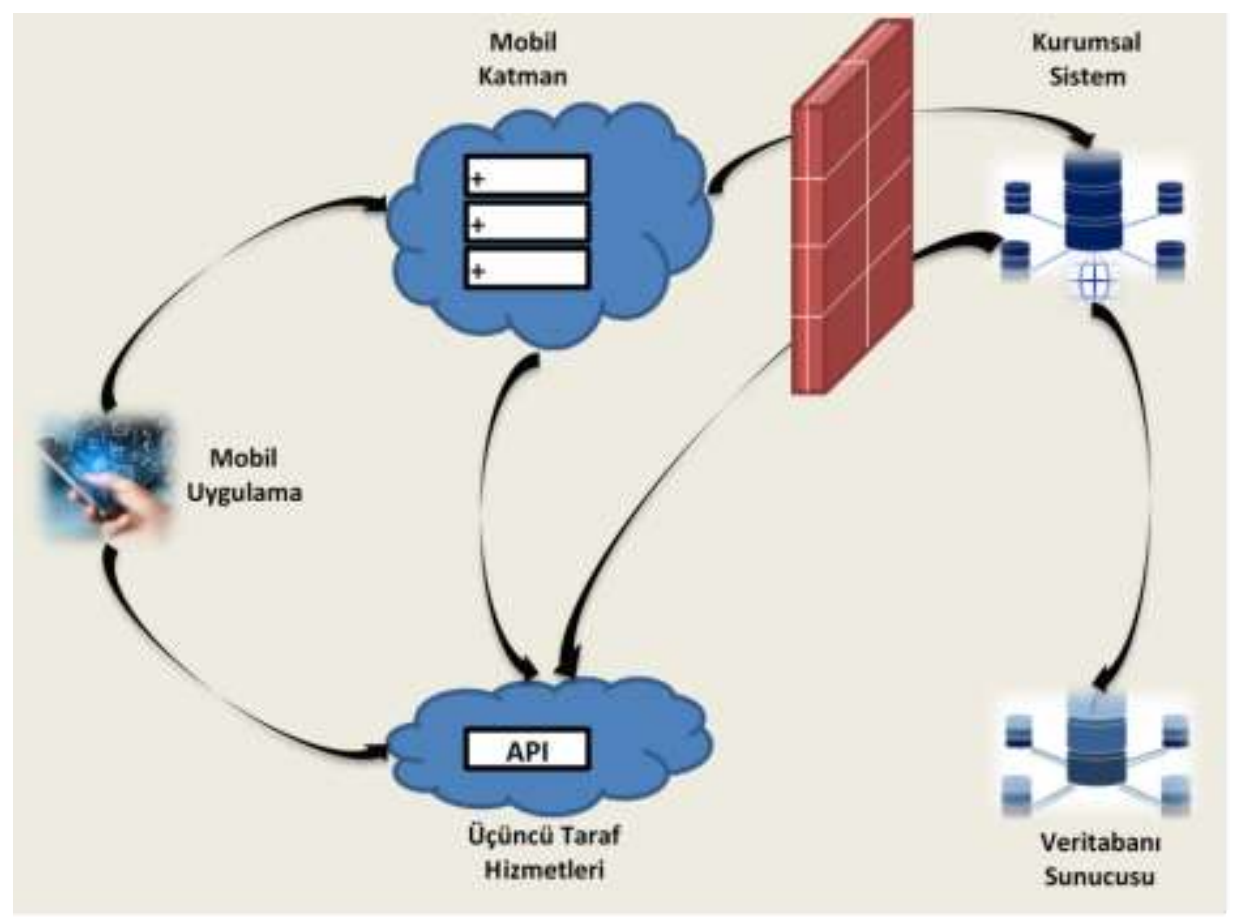

Şekil 3. Genel mobil uygulama mimarisi

Mobil cihaz optimizasyonlu web içeriği sunumu için belirli cihaza özel websitesi, cihaza özgü uygulama ve duyarlı websitesi tekniklerinden faydalanılmaktadır. İlk teknik olan belirli cihaza özel websiteleri genellikle bir alt-alan (subdomain) altında ya da alt-klasör (subfolder) içerisinde bulunur. Böylece websitesi; örneğin, yalnızca mobil cihazlar için en baştan tasarlanabilmektedir (diğer bir ifadeyle tamamen böyle bir kullanım türü için optimize olacaktır). İkinci teknikte ise masaüstü bilgisayar websitesiyle aynı içeriği kullanan, cihaza özel geliştirilmiş bir uygulama yapısı esas alınmaktadır. Son olarak, duyarlı websitesi tekniği ile esasen bir websitesi, bazı mobil cihaz özelliklerini tespit ederek ve gerçek zamanlı olarak bu özelliklere (örneğin, yazı tipi boyutlarını ve menüleri değiştirir) adapte olmaktadır [7].

\section{Entegre Mobil Uygulama-Websitesi Tasarımında Firsatlar, Teknik Zorluklar ve Önerilen Yaklaşım}

Websitesi, bireysel olduğu kadar kurumsal olarak da iş dünyasına ve başarıya açılan önemli bir kapıdır. Kurumların, şirketlerin, organizasyonların ya da ürünlerin bilgilerini tüm paydaşlara en etkili şekilde ulaştırılmasına imkân sunar. Diğer taraftan, mobil uygulamalar ise özellikle son kullanıcı katılımı için gereklidir. Websitesine daha fazla trafik çekmek ve ziyaretçileri müşterilere dönüştürmek için bu iki pazarlama kanalını kullanıcı etkileşimli olarak entegre etmek mümkündür.

Son yıllarda oldukça önemli aşamalar kaydeden mobil uygulama ve web sistem çözümlerinin özellikle entegre kullanımları ile sunulan avantajlar, beraberinde aşağıda üç başlıkta incelenen zorlukları da getirmektedir: Etkileşim, güvenlik ve ölçeklenebilirlik.

\subsection{Etkileşimli Tasarım}

Mobil uygulama ve websitesi entegrasyonu, günümüzde çok yaygın ve pratik bir etkileşim kanalı olarak kurumlar/kuruluşlar ve firmaların olduğu kadar kullanıcılar ve müşterilerin de odak noktasıdır.

Global tüketici davranış modelindeki hızlı dönüşümün bir yansıması olarak her yerde ya da herhangi bir zamanda, arzu edilen bilgilere erişmek önemli bir taleptir [1]. Mobil kullanıcıların sürekli artan sayısının yanı sıra günlük hayatın artık vazgeçilmezlerinden olan kolay ve zahmetsiz mobil uygulamalar ile bu kullanıcılara hitap etmek üzere etkileşimli tasarımlar öne çıkmaktadır. Bu yaklaşımın özünde yer alan "kullanıcılara dokunabilme" ve "son kullanıcı veri analitiği" stratejileri, iş geliştirme firsatı olarak hem websitesi kullanımını hem de trafiğini artırmanın bir yoludur. 
Mobil uygulama ve websitesi bütünleşik çözümü, ancak etkileşim desteğiyle; örneğin, şaşırtıc1 ölçüde ziyaretçileri müşterilere dönüştürerek, teknolojik bir potansiyele ve değere sahiptir. Böylece günümüzde özellikle bilgi-iletişim ve pazarlama sektörlerinin önemli bir parçası olarak artan dönüştürme oranı ve yüksek iş-süreç başarımı için anahtar rol oynaması öngörülmektedir.

\subsection{Güvenlik}

Bankacılıktan sigortaya, sağlıktan seyahate ve eğitimden savunmaya kadar tüm sektörlerde dünya çapında global ağ üzerinden işlem ve iletişim hacminin hızla artması, daha önce benzeri görülmemiş güvenlik sorunlarını tetiklemiştir.

Websitesi ve mobil uygulama bütünleşik mimarisini esas alan çözümler ise ilave güvenlik sorunlarını beraberinde getirmektedir. Özellikle kişisel bilgi sızdırılmasını engellemek üzere etkili bir websitesi ve mobil uygulama entegrasyon süreci, tüm sistem-kullanıcı isteklerine uygun olarak tasarım, gerçekleştirme, kodlama ve kimlik doğrulama yöntemleri geliştirilmesini gerektirmektedir. Bu alanda kullanılacak ya da geliştirilecek protokoller, özellikle yerel/küresel ăg, e-ticaret, kamu, askeri, kişisel ve küresel ölçekli entegre sektörler için kullanılabilirlik ve güvenilirlik isterlerine en üst düzeyde cevap vermelidir. Örneğin, parola kurtarma desteği, kullanıcılar cep telefonlarını kaybettiğinde de sunulmalidir.

Yaygın olarak bilinen güvenlik isterlerini karşılayabilecek bir kullanıcı kimlik doğrulama protokolü (örneğin, oPass), şifre çalma ve yeniden kullanım saldırılarını önlemek için kullanıcının cep telefonunu ve kısa mesaj servisini (SMS) içerir. Bu çözüm yaklaşımında kullanıcının farklı websitelerinde oturum açmak için yalnızca uzun vadeli bir parola hatırlaması gerekmektedir. Mobil uygulamalarda oPass kimlik doğrulama benzeri yöntemlerin web tabanlı güvenlik analizi yapılarak kullanıcılar için oldukça güvenilir ve grafik ya da metin şifresi tabanlı diğer bilinen alternatiflere kıyasla başarımının daha iyi olduğu kanıtlanmıştır [10].

Entegre çözüm mimarilerinde esas alınmak üzere bir uygulamanın geliştirme sürecinde yer alan araştırmacılar için kılavuz niteliğindeki değişik proaktif düzeltme stratejileri ve güvenli kodlama politikaları literatürde sunulmaktadır [11].

Her ne kadar güvenlik fonksiyonu bileşenlerinin websitesi-mobil uygulama bütünleşik tasarımında ne zaman ya da hangi aşamada planlanması gerektiği tartışma konusu olsa da genel görüş, daha ilk uygulama geliştirme safhasındayken ele alınmasının, başarımı arttırmak için en uygun olduğu yönündedir. Güvenlik unsurlarını uygulama geliştirmeye dâhil ederken, mobil uygulama geliştiricilerin dikkat etmesi gereken yedi önemli konu bulunmaktadır [12]:

- İlk aşamada gözden geçirme

- Kavramsal tasarım ve tanım aşamasında tehditleri modelleme

- Genel tasarım aşamasında güvenlik bileşenlerinin tasarımını gözden geçirme

- Tüm geliştirme aşamalarındaki kodun incelenmesi

- Uygulamanın konuşlandırılmasından önce kalite-risk değerlendirmesi

- Uygulama geliştirme riskinin azaltılması

- Sektörel ve endüstri standartları açısından iç (dâhili iyileştirmeler) ve dış (belirli bir endüstrisinde aynı benzerliği paylaşan diğer programlar) kıyaslama.

Kuşkusuz ki web uygulaması güvenliğini etkileyen birçok değişken bulunmakta ve etkileşimli mobil uygulamaların entegrasyonu ile her geçen gün bunlara yenileri eklenmektedir. Ancak, bu güvenlik açıkları, gelişen yeni stratejiler ve yöntemlerin de değerlendirildiği belirli kritik alanlarda güvenliği artırarak elimine edilebilir. Bu noktada öne çıkan önemli hususların başında ise araştırmacılar ve uygulama geliştiricilerin profesyonel bir sistem ya da yazılım çözümünü hizmete sunulduktan sonra hiçbir güvenlik güçlendirme ihtiyacına gerek duyulmayacak tasarımları öngörmesi, planlaması ve gerçekleştirmesi gelmektedir.

\section{3. Ölçeklenebilirlik}

Mobil-websitesi bütünleşik uygulama, bilginin yönetimini kolaylaştıran ve geliştiricilerin ihtiyaç duyduğu kadar bilgiyi geliştirmesine imkân sağlayan bir mimariye sahip olmalıdır. Buradaki en büyük 
gereksinim, eşzamanlı aktif kullanıcı sayısı arttıkça sistemin ve yazılımların ölçeklenebilirliğini temin etmektir.

Web servisleri sunucusuna ilave kaynaklar eklemek, ana bilişim sistemini olumsuz etkilemeden (kesintiye uğratmadan) yeni donanım bileşenleri veya özellikler ekleyerek mümkündür. Böylece genel web uygulama sistemin (backend/frontend) yüksek seviyeli ölçeklenebilirlik talepleri karşılanabilecektir [13].

Bağımsız mobil uygulamalar, sürekli işlem güncellemeleri gerektiren iş-süreç akışlarına uygun değildir. Böyle durumlarda, sistem yönetimine yardımcı olabilecek dağıtık mobil uygulamaları kullanma ihtiyacı ortaya çıkmaktadır. Spesifik sistem mimarilerini de içeren gelişmiş mobil sunucu altyapıları, mobil ortamlarda yüksek ölçeklenebilirlikte servisler sunmaktadır [8].

Büyük ve karmaşık mobil-webitesi bütünleşik uygulama mimarilerinde hem yatay hem de dikey ölçeklenebilirlik yetenekleri birlikte istenmektedir. Diğer bir ifade ile web uygulamasının daha fazla istek alabilmesi (mobil kullanıcı sayısının çarpıcı bir şekilde artmasına paralel olarak) özelliğinin yanı sıra sistem başarımına zarar vermeden yeni bileşenler ekleme yeteneği gerekmektedir.

Firmalar ya da kurumlar için büyüme ve iş geliştirme evrelerinde gelecekte karşılaşılabilecek yazılım yükseltmelerine uygun olarak esnek ve ölçeklenebilir çözümlerin tasarımı, mobil-websitesi bütünleşik uygulamaların önemli bir unsuru olmaya devam edecektir.

\section{4. Önerilen Yaklaşım ve Ölçeklenebilirlik Benzetim Çalışması Sonuçları}

Şekil 1 ve Şekil 3'te sunulan entegre mobil ve websitesi uygulama sistemlerinin, artan kullanıcı etkileşim ihtiyaçlarını en iyi şekilde karşılayacak ve güvenlik açıklarını minimize edecek mikroservisler mimarisi ile sunucusuz (serverless) yapıların birlikte etkin kullanımı, ölçeklenebilirlik için yeni bir yaklaşım olarak bu çalışmada önerilmektedir. Modelleme ve benzetim ortamı olarak NS-3 aracindan faydalanılan çalışmaların ölçeklenebilirlik sonuçları bu bölümde değerlendirilmektedir.

NS-3 benzetim aracı ile bilgisayar ağ sistemleri ayrık olay esasına dayalı (discrete event driven) olarak modellenmektedir. Desteklediği özellikler arasında sanal ă̆ yapı ve olay zamanlaması, topoloji üreteci, paket ağ sistemleri, benzetim (paket üretimi, dağıtımı vb.), dağıtık benzetim, benzetim animasyonu ve benzetim çıktı raporlaması yer almaktadır. Özellikle uygulama ve ağ katmanlarında esnek bir yapıya sahip olduğundan dolayı katmanlar arası etkileşimli modellemeler için son derece uygundur. Düğüm ya da bileşenlerin oluşturulmasında ilave özelliklerin kullanımına izin veren nitelikleri ile son dönemde geliştirilen yenilikçi çözüm önerilerinin modelleme aracı olarak ön plana çıkmaktadır.

Önerilen yaklaşımın temel unsurlarından olan sunucusuz bilgi-işlem ya da hesaplama modeli, bulut sunucu ve makine/sistem kaynaklarının tahsisinin dinamik olarak yönetildiği bir yapıdır. Diğer yandan mikroservisler mimarisinde ise uygulamalar gevşek bağlı hizmetlerin detaylı bir koleksiyonudur. Her biri kendi sürecinde çalışan ve çoğunlukla bir HTTP kaynak uygulama programlama arayüzü (API) bulunan temel mekanizmalarla iletişim kuran küçük hizmetler, böylece bu mimarinin önemli avantajlarını sağlamaktadır.

Yüksek başarım, güvenilirlik ve ölçeklenebilirlik için kapsamlı bir strateji ile Tablo 1'de sunulan örnek test veri boyutları benzetim modellerinde esas alınmıştır:

Tablo 1. Test veri seti

\begin{tabular}{lll}
\hline & Kullanıcı Sayısı & Veritabanı Öge Sayısı \\
\hline Küçük & 100.000 & 25.000 \\
Orta & 1.000 .000 & 30.000 \\
Büyük & 10.000 .000 & 40.000 \\
Çok Büyük & 100.000 .000 & 55.000 \\
\hline
\end{tabular}

Şekil 4'te, önerilen yaklaşım ve geleneksel tasarım modellerinin esas alındığı benzetim çalışmasından elde edilen sonuçlar sunulmaktadır. Geleneksel entegre mobil uygulama ve web sistem çözümünün hızla kaynakları tüketen statik yapısı, önerilen yeni yaklaşım ile özellikle artan kullanıcı sayıları ve yüksek yük altında önemli bir sorun olmaktan çıkmaktadır. Kullanıcı ve veritabanı öge sayılarının çok büyük olduğu durumlarda, önerilen yaklaşım klasik tasarım yapısına kıyasla 2 kattan daha iyi bir başarım sunmaktadır. 


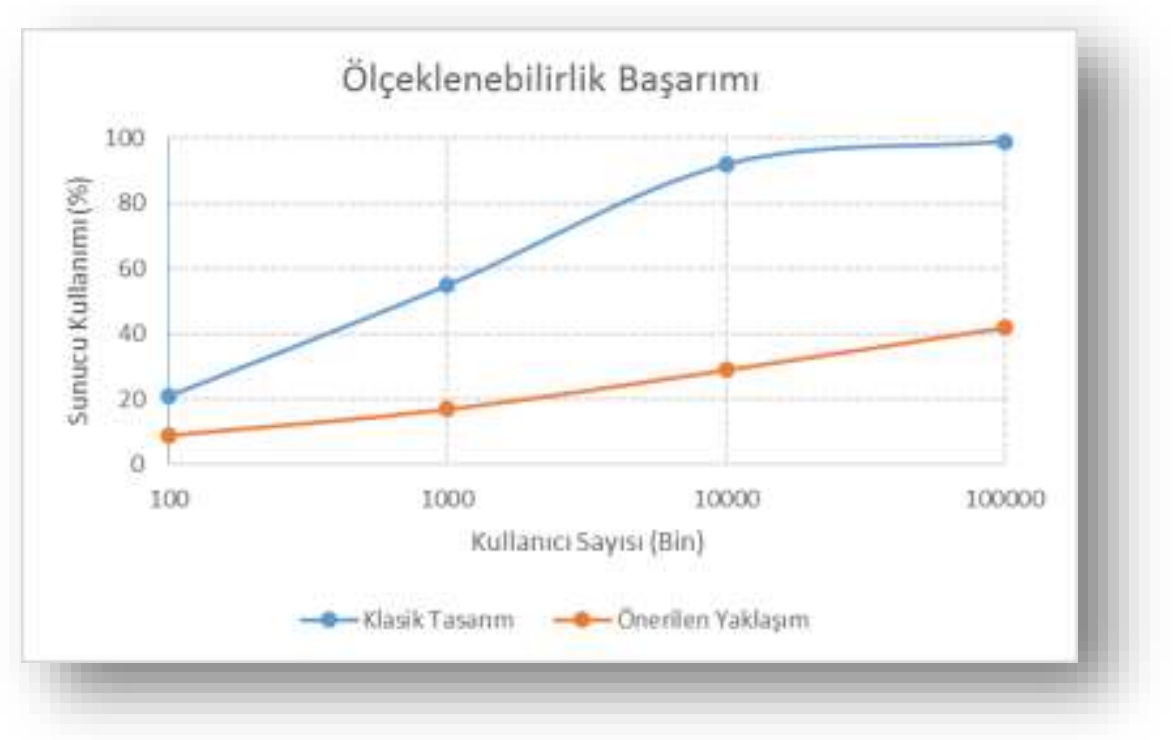

Şekil 4. Ölçeklenebilirlik başarım sonuçları

\section{Sonuç ve Değerlendirme}

Son yıllarda kullanımı hızla artmakta olan entegre mobil uygulama ve websitesi çözümleri için etkileşimli tasarım, güvenlik ve ölçeklenebilirlik boyutlarının, kurumların yanı sıra kullanıcıların beklentileri ve isterleri açısından incelendiği bu çalışmada, önemli firsatların birlikte getirdiği yeni teknik sorunların aşılmasına yönelik yaklaşımlar ile öneriler üzerinde durulmaktadır.

Bankacılıktan sigortaya, e-ticaretten e-devlete, sağlıktan seyahate, eğitimden savunmaya kadar tüm sektörlerde yerel/küresel ağ üzerinden işlem ve iletişim için geliştirilecek her yeni yazılım uygulaması ve sistem mimarisinin doğası gereği, bu üç önemli teknik bileşenin öncelikle dikkate alındığ1 yazılım geliştirme döngüsü ile yüksek başarımlı bir "web-mobil app” elde edilmesi mümkündür. Bu makalede sunulan çalışmanın sonuçları göstermektedir ki hiçbir zaman hızlı ve az (minimal) çaba ile hedefe ulaştıracak komple yani tam bir yöntem olmayacaktır. Gerçekleştirilmekte olan akademik ve profesyonel araştırmalar ile ticari ürün çalışmalarının bu sektöre uzun süreler daha yön vereceği değerlendirilmektedir.

Önerilen yaklaşımın ilk evre sonuçlarının bu makalede sunulduğu çalışmanın, kapsamlı ve başkaca başarım ölçütlerini de içerecek şekilde ileri proje olarak ele alınması ön görülmektedir.

\section{Yazarların Katkısı}

Çalışmada tüm katkı sorumlu yazara aittir.

\section{Çıkar Çatışması Beyanı}

Çalışmaya ait herhangi bir çıkar çatışması bulunmamaktadır.

\section{Araştırma ve Yayın Etiği Beyanı}

Yapılan çalışmada araştırma ve yayın etiğine uyulmuştur.

\section{Kaynaklar}

[1] Vithani T., Kumar A. 2014. A Comprehensive Mobile Application Development and Testing Lifecycle. IEEE IT Professional Conference, 22-22 May, Gaithersburg, MD, USA, 1-27.

[2] Ridder L.D. 2019. 10 Innovative Web Design Trends for 2019. https://99designs.com/blog/trends/web-design-trends-2019/ (Erişim Tarihi: 12.11.2020). 
[3] Awwwards. 2019. Web Design Trends 2019: Voice Interfaces, Image Search, Alexa and Other Crazy Things That Are Rocking Our World. https://www.awwwards.com/web-design-trends2019.html (Erişim Tarihi: 20.11.2020).

[4] Bozikovic H., Stula M. 2018. Web Design-Past, Present and Future. 41st International Convention on Information and Communication Technology, Electronics and Microelectronics, 21-25 May, Opatija, Croatia, 1476-1481.

[5] Harb E., Kapellari P., Luong S., Spot N. 2019. Responsive Web Design, Information Architecture and Web Usability. https://courses.isds.tugraz.at/iaweb/surveys/ws2011/g3-survey-resp-webdesign.pdf (Erişim Tarihi: 23.11.2020).

[6] Doyle M. 2019. Responsive Web Design Demystified. https://www.elated.com/responsive-webdesign-demystified/ (Erişim Tarihi: 25.11.2020).

[7] Perakakis E., Ghinea G., Thanou E. 2015. Are Websites Optimized for Mobile Devices and Smart TVs? 8th International Conference on Human System Interaction, 25-27 June, Warsaw, Poland, 47-53.

[8] Panfili D. 2019. Guidelines for Mobile Web Development. https://www.smashingmagazine.com/guidelines-for-mobile-web-development/ (Erişim Tarihi: 27.11.2020).

[9] StatCounter. 2019. StatCounter Global Stats: Platform Comparison from Dec 2008 to Dec 2014. http://gs.statcounter.com/\#all-comparison-ww-monthly-200812-201412 (Erişim Tarihi: 28.11.2020).

[10] Rama M., Raja S.S. 2013. Web Based Security Analysis of oPass Authentication Schemes Using Mobile Application. International Conference on Emerging Trends in VLSI, Embedded System, Nano Electronics and Telecommunication System, 7-9 January, Tiruvannamalai, India, 1-3.

[11] Fgee E.B., Elturki E.H., Elhounie A. 2012. My Security for Dynamic Websites in Educational Institution. 6th International Conference on Next Generation Mobile Applications, Services and Technologies, 12-14 September, Paris, France, 53-59.

[12] Oza H., 2019. How to Integrate Mobile Security into App Development. https://www.infosecurity-magazine.com/opinions/integrate-mobile-security-app/ (Erişim Tarihi: 29.11.2020).

[13] Lomotey R.K., Chai Y., Ahmed K.A., Deters R. 2013. Web Services Mobile Application for Geographically Dispersed Crop Farmers. IEEE 16th International Conference on Computational Science and Engineering, 3-5 December, Sydney, NSW, Australia, 151-158. 